\title{
Nudos como estrellas. \\ ABC de la imaginación ecológica en nuestras Américas Roberto Forns Broggi
}

Colección Periscopio, Editorial Nido de Cuervos, Lima, Perú, 2012, 462 págs.

\section{Tania Meneses Cabrera}

Universidad Nacional Abierta y a Distancia, Bucaramanga, Colombia.

Email: tania.meneses@unad.edu.co

Sería limitado hacer la lectura de esta obra y considerarla sólo un libro, asunto que hace un tanto problemático elaborar una reseña, y cuando afirmo que es más que un libro, me refiero a que de principio a fin, su creador nos permite vivir una experiencia artística, es decir transformadora, a través de la traducción que realiza de pensamientos y emociones, resultado de sus diversas y copiosas lecturas de textos escritos y audiovisuales, desde la perspectiva ecológica.

Usa en este ejercicio 17 de 27 letras del alfabeto en español, así que posiblemente haya espacio para continuar la obra de arte con las restantes 10 letras $(\mathrm{G}-\mathrm{K}-\mathrm{N}-\tilde{\mathrm{N}}-\mathrm{O}-\mathrm{Q}-\mathrm{W}-\mathrm{X}-\mathrm{Y}-\mathrm{Z})$, arriesgándose al uso de un estilo narrativoatrapador y creativo, a partir del imaginario social del diccionario, propone en cada aparte del texto una entrada que permite conectar diferentes temas y desarrollar lo que él llama la imaginación ecológica y la persigue a través de conexiones y relaciones que dan la posibilidad de, en palabras del autor revolotear alrededor del sentido de la vida.

La obra aporta a la ecocrítica hispanoamericana y cumple su función crítica en la medida en que actúa, desde el arte como desacomodador cognitivo y logra conformar un tejido sobre lo importante en las relaciones ecológicas, la comprensión de la unidad y el equilibrio, desde el acervo de la papa, hasta la Amazonia, pasando por el compost, el buen vivir, el cine, la cibernética, entre otros, logra estar en el pasado, en el presente y en los tiempos venideros, con sus palabras ciertas y certezas ajenas, valora el pensamiento ancestral, pero también la ciencia contemporánea y establece diálogos entre ellas.

Descubre en el trabajo de los otros la imaginación ecológica y la manifiesta en la interpretación que hace de los textos ajenos y los que construye como propios. Sentir los textos de los otros hace parte de su propuesta ecológica, entendida esta como relación, en el caso de Amazonía es evidente: 
"Con el libro Tatuaje de selva me pasó algo extraño y la única explicación satisfactoria que encuentro es que en un nivel inconsciente mis ansias de conectarme con el universo tropical requerían de un esfuerzo de mi imaginación por reproducir su energía vital. La lectura del poema reproducía el intento de capturar por un instante la riqueza biológica y cultural que está siendo borrada del mapa por la modernización de la economía amazónica, pero no se quedaba en eso."

El autor también reconoce la limitante del conocimiento y la experiencia cuando se pregunta:

“¿Sería demasiado usurpador pensar en lo selvático como algo ya propio? Al leer poemas amazónicos, siento un deseo enorme de conocer las numerosas tradiciones orales de la Amazonia y sus diferentes lenguas, de trasladarme a ese medio ambiente y lo único que puedo hacer es reconocer ese deseo en mi interior... pero ¿cómo describir lo que siento? También, ¿cómo incorporar a la ecocrítica esta conexión Amazonia que se reconoce parte de una historia ninguneada y marginal de nuestros recuentos culturales?”

En la aproximación a esta obra, retomo mis dudas de que este sea un libro, lo reconozco como una experiencia sensorial, emocional y finalmente ecológica, por su capacidad de establecer relaciones y de permitir una lectura de múltiples códigos, es difícil sumergirse en la lectura del libro, cerrar las páginas y volver a vernos nosotros mismos y a nuestro entorno con los mismos ojos.El autor trabaja desde la imaginación ecológica un contenido ético, estético y político, cuando de manera permanente, en toda su obra, pero en especial en el último texto del libro violencia lenta reflexiona sobre el gran reto de "encarar esta violencia para encarar los retos estratégicos de las calamidades ambientales”.

Este texto es también un hipertexto, ya que cada una de sus entradas, nos lleva siempre y con gran generosidad a otros lugares, autores, libros, películas, sitios web, comunidades, paisajes y múltiples territorios que amplían las fronteras de nuestra comprensión y nos permite el espacio de la imaginación, Así logra una selección muy cuidadosa y pertinente para la toma de conciencia, citando escritores, poetas, cineastas, artistas y creativos de diferentes partes del mundo para alertar sobre el trabajo de formación que se debe hacer y por esto el valor que da al papel de la crítica en su obra, un ejemplo de estas cuidadosas selecciones es el poema de Juarroz (1991),

"Hay que remodelar la casa del hombre, podarla como se poda un árbol

e introducir en su material más sensible

el delicado injerto de la vida, para que la casa crezca con el hombre y también se empequeñezca con él. 
Hay que humanizar la casa del hombre y retrasar además su destino de ruinas

Compromisoo de ser asolada por los bárbaros

que siempre la circundan, enseñándole para eso a respirar con el hombre

y hasta a vivir y morir con él.

O prepararla por lo menos

para que cuando el hombre caiga

o escape o se evapore,

la casa del hombre conserve por un tiempo

algo así como el duplicado de su imagen,

una transubstanciación o reminiscencia

de su corta memoria, hasta entregarla,

mejor que los otros hombres,

a la publicidad subliminal

de los vientos anónimos del mundo.”

El autor, hace referencia a este poema como programa de acción de un compromiso ecológico, en el que adquiere sentido la conciencia. Así mismo, en utopía amplía desde la perspectiva histórica, la importancia de los acuerdos sociales afirmando que "la utopía del siglo XXI es la utopía de los diálogos de saberes. Más que un sueño político de futuro feliz, es una utopía de la supervivencia y del cultivo del saber ambiental.”

En una entrada muy pertinente de saber ambiental insiste en comprender y validar las muchas formas en que se pueden decir las cosas, propone un saber emancipatorio, evidenciando las violencias epistémicas del pensamiento científico y reivindicando otras formas de saber, en donde parafraseando al autor, la sapiencia sea esa criatura que nos mira solamente y nos llena de alegría, y no el escenario de poder-saber en que se ha convertido. Finalmente el texto pide del lector una actitud receptiva e invita a la creación, a componer con libertad y solidaridad para comprendernos mejor y comprender mejor y más sobre el ambiente que también somos. 